\title{
INFLUENCE OF EMOTION BASED INTEGRATED LEADERSHIP ON R \& D LEADER PERFORMANCE
}

\author{
Pradeep Kumar Rout, Jyoti Ranjan Das, Monoranjan Puthal \\ Institute of Business \& Computer Studies, Siksha 'O' Anusandhan Deemed to be University, \\ Bhubaneswar, Odisha, India
}

\begin{abstract}
This study explores the dimensions of leadership in $R \& D$ organizations through studying the leadership theory and suggests an integrative approach to $R \& D$ leadership. It develops and validates a scale to access Integrated Leadership (IL) with multilevel approach for $R \& D$ organizations. Again it suggests a shorter version of the scale to assess IL. IL interacts positively to $R \& D$ performance and leader performance. Leaders' motivation, knowledge sharing, R\&D climate and HRM practices are found to boost the relationship between the IL and the R\&D outcomes and leader performance.
\end{abstract}

Keywords: Emotion, Motivation, Leadership, leader performance.

Cite this Article: Pradeep Kumar Rout, Jyoti Ranjan Das, Monoranjan Puthal, Influence of Emotion based Integrated Leadership on R \& D Leader Performance. International Journal of Mechanical Engineering and Technology 11(1), 2020, pp. 92-104.

https://iaeme.com/Home/issue/IJMET?Volume=11\&Issue=1

\section{INTRODUCTION}

Review of literature points out that there is a reason to study cognitive, personal, interpersonal and organizational factors along with leadership which have effect on R\&D performance, leader performance. Studies have found that there is a relationship between transformational and transnational nature of leadership with R\&D project success (Scott and Bruce, 1998) and scientists creative performance (Gupta and Singh, 2014). R\&D project leaders and performance of their team members have five key jobs behavior, including strategic planning, team building, gate keeping, technical expertise and championing, which have direct impact on project performance (Kim et al., 1999).

The above literature suggests that there are several other leadership dimensions beyond the conventional dimensions that are essential for R\&D performance and leader performance. Potential factors for $R \& D$ performance and leader performance can include relevant knowledge and technical skills, freedom to explore, divergent thinking, empowerment of subordinates, innovative behavior of R\&D leaders, high-quality leader-member exchange, innovative climate, strategic planning, knowledge sharing, and HRM practices. Some factors 
including cognition and grit, have been ignored while specifying R\&D leadership. The facilitative factors can be leaders' motivation, knowledge sharing among scientists, R\&D climate, HRM practices to further R\&D outcomes and leader performance.

We propose a model which specifies the combination of cognitive, personal and interpersonal factors that are the driving force towards $R \& D$ performance and leader performance. The discussion below deals with different leadership styles under the heading of Integrative leadership (IL). We used a multi-factorial approach by considering leader's cognitive abilities, leader's personal attributes and interpersonal characteristics into a single model. IL is argued to influence R\&D performance and leader performance. Positive facilitative factors are proposed in the relationship of IL with R\&D performance and leader performance.

\section{LIETRATURE REVIEW}

The cognitive competencies and capacities of leader, like problem solving abilities, articulating, and creative thinking contribute to leader performance (Mumford and Connelly 1991, Zaccaro et al. 2000). Partlow et al. (2015) have been identified a set of cognitive abilities which is responsible for performance and outcomes. Few studies have focused on the cognitive competencies of the leader. Competencies in reasoning, planning, and decision making involve in emotional situations.

The R\&D leader manages a variety of activities including those that require problem solving, decision-making, planning, and setting goals for the organization. These can be broadly categorized as cognitive competencies. The following competencies are seen as particularly important for an leader in organization: (a) the ability to define and analyze a problem, (b) pooling knowledge to solve problems, (c) the ability to understand work, (d) persistence when performing a difficult task, (e) good organization and planning skills, (f) knowing what decisions can be made independently, (g) knowing when to seek information or the help of others, (h) flexibility and receptiveness to other ideas, and (i) adaptability to the ambiguities of the task. These activities involve planning including problem solving and decision-making.

Generalizable competencies include intellectual or cognitive processes. These processes play a significant role in non-routine and loosely structured managerial problem-solving and decision-making situations. Routine procedures are normally followed without a heavy demand on cognitive competencies. Novel and non-routine problems and ambiguous situations stress the cognition difference between merely good leaders from able ones.

Successful leaders are successful at decision-making and planning. Their orientation to management is a combination of both analytic-logical, and humanistic approaches. Each of these approaches uses decision making and planning, and contributes to leadership qualities. Decision making and planning require a rational attitude, which must be objective, but humanistic approaches foster or facilitate innovative solutions which are socially relevant rather than rational and objective ones. These ideas have been discussed at length in the book by Das and Misra (2015).

A R\&D leader is faced with complex, poorly structured situations. These are not solved by routine procedures. There arises a need for synthetic or intuitive thinking rather than purely analytical and logical thinking. Simon (1987) refers to it as intuitive thinking. Intuition is not entirely a conscious and deliberate process. Nevertheless, such non-conscious processes affect decision making. Intuitive or synthetic thinking is usually seen in solving problems that involve emotions. Thus both kinds of thinking are necessary. The present study includes tasks that predominantly logical and problems that have an emotional load. 
Simon's (1987) point is that planning and decision making are not entirely rational activities. It is not only the excellence in and logic that makes a good leader a good planner. Emotional, motivational, and personality predispositions also play a part in planning.

\subsection{Plans and Structure of Behavior}

In the important book on Planning, Plans and Structure of Behavior, Miller, Galanter and Pribram (1960, p.16) defined planning as "any hierarchical process in the organism that can control the order in which a sequence of operations is to be performed."

As early as 1960, Miller, Galanter, and Pribram (1960) proposed the concept of "plan", which was like the program for a computer. However, planning was not exactly like a computer program. As the following quotation shows, “...the reduction of plans to nothing but programs is still a scientific hypothesis and is still in need of further validation" (p. 16). This brain-computer analogy has since been one of the central problems in artificial intelligence. We humans in contrast to machines are guided by motivations and emotions. Decisions cannot be solely analytical. A synthetic perspective is necessary as mentioned above.

\subsection{Logical and Affect-Laden Problems}

The model holds that mental functions of individuals are to be determined by the interaction between their neuro-mechanism and their life's experience (Luria, 1966). Subsequently, other authors followed Luria (Denes and Pizzamiglio, 1999; Gazzaniga, 1979). Mental or cognitive functions as decision making are shaped by motivations and emotions. Importantly, these contribute to learning what is socially desirable, culturally acceptable behavior. These are the central items that make up emotional intelligence.

In fact the best management decision is an integration of both modes of thinking, that is analytic-logical, and synthetic-affective. Each of these are represented in the two tasks, Crackthe-Code test and Predicament test, in the present study .

Decision making in the novel situations is a challenge in an R\&D organization. In conclusion, deliberate or rational decision requires planning, whereas emotionally loaded decisions may not proceed with components of planning as an integrated mechanism comprising representation, anticipation, execution and regulation (Das, Kar, and Parrila, 1996). The two kinds of decision making are often called hot (emotional) and cold (logical). Damasio (1994) discusses the relationship between emotion, reason and the human brain in great detail in the book Descartes' error.

\subsection{Personal Factors}

\subsubsection{Grit}

A leader possesses some individual and positive personal qualities to be successful and also to influence their subordinates to be successful. 'Grit' (Duckworth, 2007) triggers a leader to work seriously, take challenges, put effort and show interests over a period of time to achieve success. Talent and intelligence are not always and only important factor for success in many cases, rather 'grit' is also a factor that can be predictive of success. Grit is the disposition to pursue long-term goals with passion, perseverance, zeal, hard work and sustain it over a long period of time. It is an influential factor for success and predicts higher R\&D achievement (Duckworth et al., 2007). It helps the achievement of difficult goals and objectives that require sustained and focused application of talent over a long period of time. Gritter people are highly determined, passionate for their work, and continue it for longer time and show their commitments and dedication for successful outcomes. Perseverance of effort and consistency of interest (Culin et al., 2014) are two dimensions of grit. Perseverance of effort is associated with hard work, dedication and self control that lead an individual to stick and 
pursue a long-term goal until the goal is achieved. Perseverance does not deal with hourly wish (Duckworth et al., 2007). Consistency of interest deals with effort and interest over the years despite of failure, adversity, and plateaus in progress. Grit and talent are inversely related. Talented people are, average, less gritty in achieving goals. Individuals who are both extremely talented and extremely gritty are very rare (Duckworth and Eskreis-Winkler, 2014).

The R\&D leaders succeed in a challenging environment, with higher self-efficacy, judgmental power, growth mindset and they stick to a goal over a long-period of time and continuously put effort toward achieving their research goals. The R\&D projects involve high risk of failure, disruptions and setbacks but $R \& D$ leaders stick to the attainment of the research objective till they succeed.

Grit and self control are essential for high achievement involved in novel R\&D outcomes. It seems that a success and growth mindset of the leader is positively correlated with grit. Under high (low) level of grit, relations between leadership and R\&D performance will be stronger (weaker).

Grit entails the capacity to sustain both effort and interest in long-term research projects that take months or even years to complete. Grit emphases on long-term goals and persistence in the face of setbacks.

Gritty R\&D leaders were more likely to complete their R\&D projects than non-gritty leaders. Gritty leaders are likely to work harder and longer than their less gritty peers and, as a consequence, perform better. Subordinates and HRM mangers are likely to evaluate gritty leaders' performance positively than non-gritty leaders.

\subsubsection{Personal Humility and Professional will}

Collins (2001) identified five levels of people work in an organization: (1) highly capable individual, (2) contributing team member, (3) competent manager, (4) effective leader, and (5) level 5 executive (Collins, 2001, p. 20). A Level 3 leader is a competent manager who "organizes people and resources toward the effective and efficient pursuit of predetermined objectives" (Collins, 2001, p. 20). A Level 4 leader "catalyzes commitment to and vigorous pursuit of a clear and compelling vision, and stimulates the group to high performance standards" (Collins, 2001, p. 20) but they are charismatic and egocentric and do not build their successors for success. Collins (2001) defined a Level 5 leader as one who "builds enduring greatness through a paradoxical blend of personal humility and professional will" (p. 20). Such leaders are more "plow horse than show horse" (Collins, 2001, p. 39), selfefficacious and make sure that those around them are set up for success, fierce stoic resolve and are ambitious which is highly required for any organization. They are clear, modest, servant, humble, genuine, and team player. They do not seek spotlight. They desire to serve other employees with intense resolve or will. They are dedicated to the organization, a clear catalyst in achieving results and goal, and have strong work ethics and are self-motivated. These characteristics make their subordinates motivated, performance-oriented, and to work effectively for the realization of organizational goals.

\subsubsection{Technology savvy}

Goldsmith (2010) found that technological savvy is one of the five qualities of effective leaders. He has also identified four things a leader needs to do: (1) A leader must understand how to use intelligent technology and that can help the organization; (2) a leader must know the process of recruitment, development of technically competent people, and maintain them in a network; (3) a leader must know how to carry out and manage investment in new technology for the use of the organization; and (4) positive role model in leading the use of new technology. To meet the ever increasing demands of knowledge, R\&D leaders must have the capability to manage technology strategically and the ability to think strategically along 
with other skills. The ongoing structural changes have posed the need of technology savvy leaders who understand how to integrate new and emerging technologies into their organization for strategic planning to develop innovative forms of competitive advantage. The leader acquainted with new technology, creates new technology and encourages subordinates to adopt the technology for his or her and subordinates' performance vis-à-vis organizational performance.

\subsubsection{Cultural sensitivity}

In globalized R\&D organizations, the leader has to deal with employees from diverse cultures and backgrounds. Unless the leader understands and appreciates the cultural differences in behavior, symbols and practices; she or he cannot be effective to work in collaboration with other R\&D laboratories, different research teams or groups formed within the country and across the globe. A R\&D leader has to work with a diverse population, belonging to different cultures with diverse heritages, value systems, food, languages, and work habits. Such cultural sensitivity of the leader will drive the subordinates toward work and improve the R\&D performance.

\subsection{Interpersonal Factors}

\subsubsection{Transformational leadership}

Leadership is a relationship between leaders and subordinate and a distinctly interpersonal phenomenon (Mumford et al., 2000). It has been widely accepted from the leadership theory that, leadership, behavior and ability influences R\&D performance and leader performance and research project success (Keller, 1992; Scott and Bruce, 1998; Tierney et al., 1999). It is theorized that, the leader's behaviors and traits directly influence the subordinates and organizational outcomes (Lee, 2007). As R\&D people are a special group of human resources, some leadership attributes are highly influential and some are less influential. Transformational leadership of Bass (1985), measured by with their Multifactor Leadership Questionnaire (Bass and Avolio, 1990), has a positive impact on R\&D team performance (Lee, 2007). Transformational leadership style influences subordinates. The leader and subordinates propel one another for organizational goal attainment. The transformational R\&D project leaders, who provide a inspirational vision and intellectual stimulation to their subordinates, are associated with R\&D project success.

As R\&D team operates autonomously in a R\&D organization; the leader's changeoriented, interpersonal behaviors positively influence subordinates performance (Keller, 2006), job satisfaction and R\&D outcomes (Shain and Zhou, 2003). The transformational leader has the competency to inspire and motivate the subordinates for higher performance and acts as a mentor, teacher, counselor, and trainer to achieve R\&D performance (Bass, 1985; Yukl, 2002). The leader shows the vision, creates enthusiasm (Bass, 1986) and avenues for subordinates' commitment to achieve success beyond normal expectations (Keller, 2006).

\subsubsection{Leader member exchange (LMX):}

LMX is a leadership quality otherwise known as social exchange approach. It is the quality of relationship experienced between a leader and subordinates. It is a relational aspect of leadership and high quality exchange process focuses on good relations between the leader and subordinates (Graen and Cashman, 1975; Lee, 2007). This social exchange process posits that leader-subordinate relationship positively predict a leader's effectiveness, organizational performance (Graen and Scandura,1987), and subordinates' job satisfaction. The high quality of LMX relationship increases the creative performance (Tierney et al., 1999) and research project success (Elkins and Keller, 2003). There exists a positive effect of LMX on R\&D performance (Lee, 2007). It is the behavioral aspect of leadership which focuses on the leader's behaviors that directly impact on organizational outcomes. It involves a high degree 
of friendship, mutual trust, loyalty, respect, and good understanding of mutual commitment. In this process, the leader can develop a high quality relationship with subordinates to yield high R\&D outcomes. Through this relationship, leaders and subordinates get an opportunity to discuss novel ideas freely, exchange $R \& D$ related information, and interim $R \& D$ results which lead to greater team performance. The subordinates' perception of high quality exchange relationships is associated with innovation and creativity (Scott and Bruce 1994). An exchange relationship established between the supervisor and subordinates depends upon the perceptions of trustworthiness and loyalty among them (House and Aditya, 1997). Evidence suggests that high quality LMX in R\&D is related with innovation and creativity of subordinates in the face of challenging tasks (Duchon et al., 1986; Graen and Cashman, 1975; Liden and Graen, 1980). Effective exchange relationships associate with patent disclosures, intrinsic motivation and use of required cognitive problem-solving strategies (Graen et al., 1982).

A mature, stable, and high quality relationship is established between the leader and subordinates for successful execution of R\&D projects which leads to high quality $R \& D$ outcomes. The leader and the subordinates start forming a meaningful relationship where both influences each other attitudes and behaviors, and a shared reality emerges between the two parties (Graen and Scandura, 1987; Scandura and Lankau, 1996). The leader delegates the duties and responsibilities to the subordinate to complete challenging and rewarding tasks, with full trust on subordinates' success in that task. The leader and subordinates reciprocate to carry out the duties and responsibilities even in the absence of team member. This can accelerate the R\&D performance and the team performance.

\subsubsection{Justice orientation}

Justice is concerned with the perception of an employee for fair treatment by the organization. Greenberg (1993) emphasizes the organizational justice for the effective functioning of an organization. Organizational justice comprises of three broad dimensions distributive, procedural, and interactional (Cohen et al., 2001; Masterson et al., 2000; Wang et al., 2010). Distributive justice focuses on the fairness of organizational outcomes such as payment and promotions, rights and responsibilities. It also ensures that, rewards and benefits are rationalized based on R\&D outcomes. Procedural justice stresses the fairness of the process by which the outcomes are achieved. It is adopted during the formation of policies and rules, ensures that the formation is in accordance with principles, values, and morality. Interactional justice includes interpersonal behaviors between the leader and subordinates during the implementation of procedures like being truthful to subordinates and sensitive to the personal needs of team members. With such justice orientation, the leader is likely to be evaluated positively and subordinates are likely to work effectively for R\& D outcomes.

\subsubsection{Emotional intelligence}

Emotional intelligence comprises of personal and the interpersonal competencies (Goleman, 2011). Empathy and social skills can be equated with leadership. Empathy putting oneself in other person's shoe and understand him or her. Social skill is more concerned with individuals' ability and proficiency to manage relationships and building networks. It is the friendliness with a purpose to achieve the organizational objectives.

Empathy is associated with thoughtful consideration of employee's feelings along with other factors in the process of making decisions. Empathy is the capacity to share, react, and understand the lived experiences of others (Davis, 1994). It is identified listening (Salem, 1982) and openness, reflection (Fuslier, 1988), and social judgment (Krulewitz, 1982). In a team-based environment, a leader with empathy is sensitive to others' view points and freedom of expression. Accordingly, a leader with empathy can develop strong teams that can work together to achieve organizational goals. Without empathy in cross cultural settings, 
employee's interactions can generate misunderstanding. Empathetic leaders can provide difficult feedback for better performance and better communication. Empathy is essential for team-based job and talent retention.

Social skill is more concerned with individuals' ability to manage relationships. Social skill is a proficiency in managing relationships and building networks. With it, the leader builds social networks with others. It is the friendliness with a purpose for moving people in a desired direction. Socially skilled leaders are connected in a social network and are capable of managing teams through social interactions. They build bonds widely because they know that this may help them someday. Such abilities of the leader is likely to be evaluated positively and improve R\&D performance.

\subsubsection{Authentic behavior}

An authentic leader cultivates honesty, loyalty, equality, altruism, kindness fairness (Yukl, 2011), integrity (Gardner et al., 2005), and takes ethical decisions (Hannah et al., 2005). The authentic leaders act with transparent decision making, confidence, optimism, hope, resilience, and consistency with their subordinates and colleagues (Avolio et al., 2005). The authentic behavior of a leader increases team bonding and heightens performance. The leader's ethical and values-based behaviors improve subordinates' performance and enhance their self-awareness, self-regulation, self realization for sustained performance (Watson, 2003; Avolio et al., 2005).

Authentic leaders create healthy work environments which fosters subordinate's work engagement and development (Wong and Cummings, 2009). Authentic leadership is positively related to subordinates' moral courage (Hannah et al., 2011). Bass (1999) conceptualized authentic leadership by linking the four components of transformational leadership with authentic behavior of the leader on the basis of moral character of the leaders for the self and the others.

Authentic leadership style includes optimism, expanded thinking, and increased selfawareness, and self regulation to make decisions (May et al., 2003). Self-awareness is the basis of the leadership. It refers to the understanding one's own talents, strengths, sense of purpose, core values, and beliefs (Gardener et al., 2005; Walumbwa et al., 2008). It fosters relationship with subordinates on the basis of mutual trust and transparency. The leadership can be successful if genuine, transparent actions of the leader are focused on subordinates' and organizational development and performance (Walumbwa et al., 2008).

Authentic leadership has three major dimensions (Walumbwa et al., 2008): (1) transparency, (2) moral and ethical conduct, and (3) balance processing. (1) The leader encourages transparency at work with colleagues and team members and are also honest and truthful before taking any decision. The leader maintains a level of openness with their subordinates and provides them opportunities to approach their ideas and challenges in the workspace. (2) The leader sets and maintains a high standard of moral and ethical conduct in the workspace.

The uni-dimensional motivation construct, each of the five dimensions knowledge sharing, each of the nine dimensions of R\&D climate and each of the six dimensions of HRM practices had acceptable convergent validity $(\mathrm{AVE}>=.50)$ and composite reliability $(>=.70)$. Therefore, the items measuring each variable of the moderators had acceptable convergent validity and composite reliability (Table 1 ). 
Influence of Emotion based Integrated Leadership on R \& D Leader Performance

Table 1 Moderators influencing R\&D performance and leader performance

\begin{tabular}{|c|c|c|c|c|c|}
\hline Step 2 & Path & Coefficients & $\mathbf{t}$ & $\mathbf{p}$ & Inference \\
\hline & Motivation -> R\&D performance & .08 & 1.36 & .17 & $\mathrm{H}_{2.1}(1 \mathrm{a})$ refuted \\
\hline & Motivation - > Leader performance & .03 & .65 & .51 & $\mathrm{H}_{2.1}(\mathrm{lb})$ refuted \\
\hline & R\&D climate -> R\&D performance & .26 & .72 & .469 & $\mathrm{H}_{2.1}(3 \mathrm{a})$ refuted \\
\hline & HRM practices -> R\&D performance & 1.29 & 1.13 & .198 & $\mathrm{H}_{2.1}(4 \mathrm{a})$ refuted \\
\hline & HRM practices -> Leader performance & .13 & .70 & .482 & $\mathrm{H}_{2.1}(4 \mathrm{~b})$ refuted \\
\hline
\end{tabular}

$* \mathrm{p}=<.05, * * \mathrm{p}=<.01, * * * \mathrm{p}=<.0001$

The moderator effect were tested in accordance with Baron and Kenny (1996) in the three step approach. First, as reported earlier (Table 3.4) the IL predicted the R\&D performance and leader performance. Second, the moderators of the leader's motivation, knowledge sharing, R\&D climate, and HRM practices did not predict the R\&D performance and the leader performance. Only exception was that favorable R\&D climate positively predicted leader performance (Table 1). Except this, the findings refuted the first part of the second hypothesis. In the third step, the latent variable score were multiplied with the moderators of the product indicator approach. It was not restricted to formative indicators and was applied to reflective indicators in PLS-SEM (Hair, Hult, Ringle, and Sarstedt, 2014, p. 266). In the third step, all the moderators interacting with IL significantly predicted R\&D performance and leader performance. Under high (low) level of leader's motivation, knowledge sharing, favourable (unfavorable) organizational climate, and adequate (inadequate)HRM practices, IL predicting R\&D and leader performance was strengthened (weakened).These findings supported the second part of the second hypothesis (table 2).

Table 2 Interaction of IL with moderators predicting performance

\begin{tabular}{|c|c|c|c|c|c|}
\hline Step3 & Path & Coefficient & $\mathbf{t}$ & p & Inference \\
\hline & $\begin{array}{c}\text { IL } x \text { Motivation --> R\&D } \\
\text { performance }\end{array}$ & .83 & $25.459^{* * * *}$ & .001 & $\mathrm{H}_{2.2(1 \mathrm{a}) \text { supported }}$ \\
\hline & $\begin{array}{c}\text { IL x Motivation --> Leader } \\
\text { performance }\end{array}$ & .92 & $28.942^{* * * *}$ & .001 & $\mathrm{H}_{2.2}(1 \mathrm{~b})$ supported \\
\hline & $\begin{array}{c}\text { IL } x \quad R \& D \text { climate }-->R \& D \\
\text { performance }\end{array}$ & .99 & $3.580^{* * *}$ & .001 & $\mathrm{H}_{2.2}(3 \mathrm{a})$ supported \\
\hline & $\begin{array}{c}\text { IL x R\&D climate --> Leader } \\
\text { performance }\end{array}$ & .88 & $3.402^{* * *}$ & .001 & $\mathrm{H}_{2.2}(3 \mathrm{~b})$ supported \\
\hline & $\begin{array}{l}\text { IL x HRM practices --> R\&D } \\
\text { performance }\end{array}$ & .80 & $6.912^{* * *}$ & .001 & $\mathrm{H}_{2.2}(4 \mathrm{a})$ supported \\
\hline & $\begin{array}{c}\text { IL x HRM practices --> Leader } \\
\text { Performance }\end{array}$ & .79 & $8.059^{* * *}$ & .001 & $\mathrm{H}_{2.2}(4 \mathrm{~b})$ supported \\
\hline
\end{tabular}

After testing the moderators, each time one interaction term was introduced in the relation of IL $\rightarrow$ R\&D performance and IL $\rightarrow$ leader performance. It was compared with the beta-value and R-square of the IL predicting R\&D performance and leader performance (Table 3.8). When IL was multiplied with the leaders' motivation, the interaction term predicted the R\&D outcomes and leader's performance. Similarly were the cases when IL was multiplied with knowledge sharing, R\&D climate and HRM practices (Table 3.8).

While IL explained $62 \%$ of $\mathrm{R} \& \mathrm{D}$ performance and $80 \%$ of leader performance, additionally, the interaction term of IL with the leader motivation explained $67 \%$ of $R \& D$ 
performance and $81 \%$ of leader performance. Similarly, the IL interacting with knowledge sharing and explained $69 \%$ of R\&D performance and $81 \%$ of leader performance. The IL interacting with the R\&D climate explained $69 \%$ of $R \& D$ performance and $82 \%$ of leader performance and the IL interacting with HRM practices explained $70 \%$ of R\&D performance and $82 \%$ of leader performance (Table 3.8). In all the cases, with bootstrapping, t-values were significant.

The change in R-square along with the beta-values suggested that each interaction term explained additional variance of $\mathrm{R} \& \mathrm{D}$ performance and leader performance. The additional variances were maximum up to $8 \%$ for R\&D performance and $2 \%$ for leader performance. Inspecting the additional variances, it was observed that the interaction of IL with leader motivation was the weakest moderator that explained additional $5 \%$ of variance and the interaction of IL with HRM practices was the strong moderator that explained 8\% additional variance beyond IL $\rightarrow$ R\&D performance relations. Similarly, the moderator of leader motivation explained $1 \%$ of additional variance and R\&D climate and HRM practices each explained $2 \%$ of additional variance beyond IL $\rightarrow$ leader performance relations. Because the interaction term explained less than $9 \%$ of (.30x.30) of the additional variance, the moderators had week effect on IL $\rightarrow$ R\&D performance as well as IL $\rightarrow$ leader performance relations.

\section{RESULTS AND DISCUSSION}

Studding 139 R\&D leaders and 417 subordinates of 24 R\&D organizations in India, this study develops and validates a scale for accessing IL. Based on attributes and behaviors of relevant leadership theories, IL encapsulates the cognitive abilities, personal attributes, and interpersonal behaviors of $R \& D$ leaders. IL promotes $R \& D$ performance and leader performance. Cognitive ability of the leader was the most important positive predictor of R\&D outcomes and grit was the most important positive predictor of leader performance. Though the motivation of leaders, knowledge sharing, R\&D climate and HRM practices of $R \& D$ organizations do not relate to $R \& D$ outcomes and leader performance, interaction of the former constructs with IL positively predicts R\&D outcomes and leader performance. Accordingly, the high(low) levels of motivation, knowledge sharing, R\&D climate, and HRM practices raise (diminish) the positive impact of IL on R\&D outcomes and leader performance. However, all these moderators had weaker effects.

\subsection{Leadership Scale}

The IL incorporates with 11 dimensions of cognitive, personal and interpersonal levels. The cognitive dimension incorporates planning and decision making in a creative $R \& D$ environment. The leader's cognitive ability helps a leader to create new ideas, plan R\&D projects, articulate the ideas, make decision and execute decisions. Personal dimensions includes grit, personal humility and professional will, technology savvy and cultural sensitivity. Grit referred as perseverance of effort and consistency of interest for a long term R\&D project. Observing the personality and behavior of the leader, it motivates the subordinates to do the job as the leader does. Personal humility and professional will of a leader inculcates to avoid aggressiveness, show genuineness and intense desire to complete the project timely. Technology savvy of the leader motivates subordinates to adopt new technologies for R\&D projects. The cultural sensitivity makes the leader effective to deal with subordinates from diverse cultures or societies.

\subsection{Leadership Dimensions and Performance}

Though cognitive abilities are referred earlier in leadership research (Mumford and Connelly, 1991 and Zaccaro et al. 2000) dimensions are identified as complex problem-solving skills 
including problem identification, information integration and organization, solution construction, solution evaluation and solution execution. Here the inclusion of planing and decision making has found to be the dimensions of IL which potently further R\&D outcomes. The nature of work in $R \& D$ is innovative, unconventional, and includes high levels of uncertainty, persuasion, and politics in discovery of novel products, processes and services. Without proper planning and decision-making abilities the R\&D leader cannot execute the research task through subordinates. These are essential for articulation of ideas, defining and analyzing research problems, rationalizing social relevance, and persistence in performance of novel R\&D tasks. The planning abilities of the leader help conceptualizing new R\&D projects and their execution. The decision-making abilities of the leader help to think of multiple solutions for $R \& D$ projects and chose the best solution that is justified and socially appropriate. Planning and decision-making potentially reflects IL that improves R\&D and leader performance.

R\&D organizations need a updated and technology-driven leadership. A technology savvy leader is effective for his or her adoption of more advanced and new technology which creates new knowledge. R\&D works are connected with deployment of new technologies of information sciences to rocket sciences in R\&D projects. Technology is changing and it calls for deployment of new technologies to improve performance. If the leader is not technology savvy, he or she cannot motivate others for adoption and deployment of new technologies. A technology savvy leader updates and improves the technology for present and future R\&D project performance.

A leader, being cultural sensitive, displays more appropriate behavior towards subordinates from diverse societal backgrounds. The subordinates who work in a R\&D team are from different locations, have different value system and various cultural practices. If the leader is not sensitive to the various cultural backgrounds of subordinates, he or she will not be effective in dealing and mobilizing the subordinates for research endeavors.

The interpersonal behaviors are extensively studied in leadership research, and those predict R\&D performance and leader performance (Bass and Avolio, 1990). Transformational behaviors are change-oriented behaviors. Transformational leaders inspire, intellectually stimulate the subordinates, and take steps to remove the deficiency of subordinates for higher performance (Bass, 1990). If the leader does the process in idealized behavior and attributes, the subordinates will not consider the leader as a role model. The leader provides a vision for achievement of organizational goals and streamlines the activities for achievement of the goals. The leader changes the subordinates' perspectives for finding out novel solutions for emerging and existing problems, makes the subordinates creative through inspirational motivation, pushes his or her team for higher-level of performance beyond expectations and subordinates release effort unconditionally for task completion.

LMX is a high quality relationship based approach in leadership which signifies a process and interactions between leaders and their subordinates (Graen and Uhl-Bien, 1995) which has direct impact on R\&D performance and outcomes. If a leader maintains the quality relationships with subordinates, those can trigger job satisfaction, job commitment, and performance. Scientists and engineers like to work with their leader that can boost R\&D and leader performance.

\subsection{Shorter Version of Leadership Scale}

The IL scale has 11 dimensions and 79 items. This becomes problematic to administer in R\&D organizations. Therefore, it calls for a shorter version of the scale. IL relates positively to $\mathrm{R} \& \mathrm{D}$ outcomes and leader performance. These findings provide a concurrent validity to the scale. When the 11 dimensions were linked to $R \& D$ outcomes, cognitive ability, authentic 
behavior, personal humility positively predicted R\&D outcomes; personal humility and grit positively predicted leader performance. These dimensions include the cognitive factor of planning and decision-making, personality traits of grit and humility, and behavioral dimensions of authenticity. Incorporating these four dimensions--cognitive abilities, humility, grit, authentic behavior, a shorter version of the scale can be used to assess the attributes of IL among R\&D leaders. Training, counseling, and coaching can be provided to improve their abilities, traits, and behavior to make them effective in $R \& D$ organizations.

\subsection{Moderators}

The scientists are self motivated internally and they can motivate others to promote team performance vis-a-vis R\&D performance. The IL encourages growth and success mindset for scientists. In the process, scientists develop their mastery that furthers R\&D and leader performance. Because scientists and engineers are self-motivated and have passion for their work, the motivation of the leader marginally contributed to improve the IL positive relations with performance.

HRM practices are found to have a positive impact on organizational performance and productivity (Katou, 2011; Huselid, 1995) and enhance employee commitment and motivation (Savoncvicience and Stankeviciute, 2011). HRM practices of performance-based reward system and recognition, flexible working arrangements, and career development are found to influence employees' motivation (Minbaeva, 2008). HRM practices can attract talented scientists. Congruent with earlier literature, HRM practices, including recruitment and selection, training and career development, compensation practices, performance appraisal, promotion policy, grievance procedures, have facilitated the positive relations of IL with $R \& D$ performance and leader performance.

The study suggests the IL predicts the R\&D performance. That means the more leadership quality a scientist posseses, the more $R \& D$ performance can be expected. The leader performance is a qualitative measure for $R \& D$ leaders. It is difficult to measure $R \& D$ performance because the $R \& D$ projects are unambiguous, unpredictable and turbulent. It is measured quantitatively in terms of patent filed, research published, citations received, technology, product, and process developed. Measuring R\&D outcomes quantitatively, leader performance qualitatively, this study refrains that a high level HRM practices improves the relationship of IL with R\&D performance and leader performance. HRM practices in R\&D organizations have more improved this relationship. Therefore, HRM practices can be improved to further the association of IL with performance.

\section{IMPLICATIONS}

Promoting the IL through coaching, counseling and training can improve the R\&D performance and the subordinates evaluation of the leader. Because subordinates are self motivated knowledgeable employees, facilitates factors like improving HRM practices can improve the R\&D performance and leader performance.

\section{LIMITATION AND SCOPE FOR FUTURE RESEARCH}

This study is not free from limitations. First, the self-reported responses to the questionnaire may not be free from social desirable responding. Moreover, the leaders were the heads of research department, team, group and the subordinates were those who worked directly under the leader. In many research organizations, the Heads of Department, team, group are rotated in a fixed time interval. This short duration in leadership position might have affected the replies to the statements and questions. However, the leader responded to certain statements and questions, and subordinates responded to other statements or questions about the leader, 
that procedurally arrested the common method bias. Second, the IL questionnaire containing 79 items may not be easy for administration to assess leadership in R\&D organizations. Keeping the importance of the contributing factors to $R \& D$ performance, a shorter version can be developed, validated and used to assess IL in R\&D organizations. This may include cognitive abilities of planning and decision-making, personality traits of grit and humility, interpersonal attributes of empathy, social skills and authentic behavior. Further, IL which is found to be in R\&D units with knowledge employees may not be so important in the manufacturing and service sector. This calls for replication of finding beyond R\&D organizations. Third, while four moderators have been studied, psychological capital, encompassing optimism, hope, self-efficacy, and resilience can be a possible moderator in the relationship of IL with R\&D performance and leader performance.

\section{CONCLUSION}

This study identifies the cognitive abilities, personality traits, and interpersonal behavior of R\&D leaders. The study has developed a scale that can be used to access R\&D leadership. The study suggests the IL predicts R\&D performance and leader performance. Additionally, HRM practices are found to be a potential moderator to promote the relations IL with R\&D performance and leader performance. If the leader, model his or her behavior in accordance with IL, he or she can improve R\&D performance and facilitative HRM practices can further such performance.

\section{REFERENCES}

[1] Allen, T., Katz, R., Grady, J. J., \& Slavin, N. (1988). Project team aging and performance: The roles of project and functional managers. $R \& D$ Management, 18(4), 295-308.

[2] Andrews, F. M., \& Farris, G. F. (1967). Supervisory practices and innovation in scientific teams. Personnel Psychology, 20(4), 497-515.

[3] Ángel, P. O., \& Sánchez, L. S. (2009). R\&D managers' adaptation of firms' HRM practices. $R \& D$ Management. 39(3), 271-290.

[4] Avolio, B. J., \& Gardner, W. L. (2005). Authentic leadership development: Getting to the root of positive forms of leadership. The Leadership Quarterly, 16(1), 315-338.

[5] Barczak, G., \& Wilemon, D. (1989). Leadership differences in new product development teams. Journal of Product Innovation Management: An International Publication of the Product Development \& Management Association, 6(4), 259-267.

[6] Barnowe, T. (1975). Leadership and performance outcomes in research organizations: The supervisor of scientists as a source of assistance. Organizational Behavior and Human Performance, 14, 264-280.

[7] Bock, G. W., Zmud, R. W., Kim, Y. G., \& Lee, J. N. (2005). Behavioral intention formation in knowledge sharing: Examining the roles of extrinsic motivators, socialpsychological forces, and organizational climate. MIS Quarterly, 87-111.

[8] Brachos, D., Kostopoulos, K., Eric Soderquist, K., \& Prastacos, G. (2007). Knowledge effectiveness, social context and innovation. Journal of Knowledge Management, 11(5), $31-44$.

[9] Buijis, J. (2007). Innovation leaders should be controlled schizophrenics. Creativity and Innovation Management, 16, 203-210.

[10] Das, J. P., \& Misra, S. B. (2014). Cognitive planning and executive functions: Applications in management and education. SAGE Publications India. 
[11] Davis, M.H. (1994). Empathy: A social psychological approach. Madison, WI: Brown and Benchmark.

[12] De Dreu, C. K. W., Baas, M., \& Nijstad, B. A. (2012). The emotive roots of creativity: Basic and applied issues on affect and motivation. In M. D. Mumford (Ed.), Handbook of organizational creativity (pp. 217-240). San Diego, CA: Elsevier.

[13] De Jong, J.P.J. and Hartog, D.N.D. (2007), "How leaders influence employees' innovative behavior", European Journal of Innovation Management, 10(1), 41-64.

[14] Delaney, J. T., \& Huselid, M. A. (1996). The impact of human resource management practices on perceptions of organizational performance. Academy of Management Journal, 39(4), 949-969.

[15] Engwall, M., Kling, R., \& Werr, A. (2005). Models in action: how management models are interpreted in new product development. $R \& D$ Management, 35(4), 427-439.

[16] Ellison, R.L., James, L.R. and Carron, T. (1970) Prediction of R\&D Performance Criteria with Biographical Information. Journal of Industrial Psychology, 5(1), 37-57.

[17] Elliott, R. (2003). Executive functions and their disorders: Imaging in clinical neuroscience. British Medical Bulletin, 65(1), 49-59.

[18] Fuselier, G. D. (1988). Hostage negotiation consultant: Emerging role for the clinical psychologist. Professional Psychology: Research and Practice, 19(2), 175-179.

[19] Gazzaniga, M. S. (1979). Handbook of behavioral neurobiology. Vol. 2, Neuropsychology. Plenum.

[20] Gochhayat, J., Giri, V. N., \& Suar, D. (2017). Multilevel leadership and organizational effectiveness in Indian technical education: the mediating role of communication, power and culture. International Journal of Leadership in Education, 20(4), 491-505.

[21] Salovey, P., \& Mayer, J. D. (1990). Emotional intelligence. Imagination, cognition and personality, 9(3), 185-211.

[22] Scott, W A (1962). "Cognitive complexity and cognitive flexibility". American Sociological Association 25(2), 405-414.

[23] Simon, Herbert A. (1987) "Satisficing", in John Eatwell; Murray Milgate; Peter Newman (eds.), The new Palgrave: A dictionary of economics, 4(1), 243-245.

[24] Tierney, P., Farmer, S. M., \& Graen, G. B. (1999). An examination of leadership and employee creativity: The relevance of traits and relationships. Personnel psychology, 52(3), 591-620.

[25] Watson, T. J. (2003). Ethical choice in managerial work: The scope for moral choices in an ethically irrational world. Human Relations, 56(3), 167-185.

[26] Yi, J. (2009). A measure of knowledge sharing behavior: scale development and validation. Knowledge Management Research \& Practice, 7(1), 65-81.

[27] Yukl, G. (2011). Leadership in organizations. India: Dorling Kindrsley Pvt. Ltd. 